\title{
Transition metal- and solvent-free synthesis of unsymmetrical diaryl sulfides and selenides under ball-milling
}

\author{
Nirmalya Mukherjee, Tanmay Chatterjee and Brindaban C. Ranu* \\ Department of Organic Chemistry, Indian Association for the Cultivation of Science, \\ Jadavpur, Kolkata-700032, India \\ E-mail:ocbcr@iacs.res.in
}

Dedicated to Professor Dr. J. S. Yadav on his $65^{\text {th }}$ birthday

DOI: http://dx.doi.org/10.3998/ark.5550190.p009.238

\begin{abstract}
A transition metal- and solvent-free procedure for the reaction of aryl diazonium tetrafluoroborates and thiols or selenols over alumina surface under ball-milling at ambient temperature, has been developed for the synthesis of unsymmetrical diaryl or aryl-alkyl sulfides and selenides. A wide range of functionalized diaryl or aryl-alkyl sulfides and selenides were obtained in high yields and high purity within a short reaction time (5-8 $\mathrm{min}$.) by this protocol.
\end{abstract}

Keywords: aryl diazonium tetrafluoroborates, thiols, selenols, unsymmetrical diaryl sulfides and selenides, ball-milling

\section{Introduction}

The aryl-chalcogen bond forming reactions leading to the formation of aryl chalcogenides have received considerable attention because of their potential biological, pharmaceutical and material importance. ${ }^{1-4}$ Moreover organic chalcogenides have useful applications in organic synthesis as intermediates ${ }^{5}$ and catalysts. ${ }^{6}$ Hence there has been an obvious interest towards the development of synthetic methodologies for the synthesis of these compounds.

The majority of the reported protocols involved transition metals like $\mathrm{Pd},{ }^{7-8} \mathrm{Cu},{ }^{9-12} \mathrm{Ni},{ }^{13-15}$ and $\mathrm{Fe}^{16-18}$ in the reaction of aryl halides or aryl boronic acids to form chalcogenides. But few transition metal-free procedures were also reported for the reaction of aryl diazonium salts and lithium, sodium and potassium salt of arene thiolate / selenolate/ tellurolate. ${ }^{19-21}$ But these methods are associated with the use of hazardous organic solvents and toxic arene selenolate and tellurolate. Recently, S. Kumar et al. have developed a better alternative for the synthesis of unsymmetrical diaryl chalcogenides by transition metal-free reaction of arenes and diaryl dichalcogenides under oxidative condition using $\mathrm{K}_{2} \mathrm{~S}_{2} \mathrm{O}_{8}$ in TFA at room temperature or $80{ }^{\circ} \mathrm{C} .{ }^{22}$ 
Recently, ball-milling (intense mechanical grinding) has received considerable attention as a green tool for effecting solvent-free chemical reaction. ${ }^{23-25}$ For last few years we are actively engaged in exploring reactions under ball milling ${ }^{26-28}$ and lately we have reported ${ }^{29}$ a solvent, metal- and ligand-free synthesis of unsymmetrical diaryl chalcogenides by the reaction of aryl tetrafluoroborates and diaryl dichalcogenides under ball-milling. We report here an alternative method for the synthesis of unsymmetrical diaryl sulfides and selenides by the reaction of aryl tetrafluoroborate with thiol and selenol on alumina surface in presence of a base under ball milling (Scheme 1).

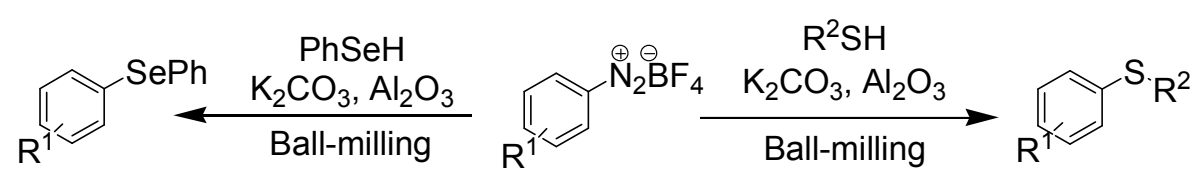

Scheme 1. Synthesis of unsymmetrical sulfides and selenides under ball-milling.

\section{Results and Discussion}

To optimize the reaction conditions, a series of experiments were carried out with variation of grinding auxiliary, base and time- for a representative reaction of 4-methoxybenzene diazonium tetrafluoroborate and 4-bromothiophenol. The results are summarized in Table 1. A variety of bases including $\mathrm{NaOH}, \mathrm{KOH}, \mathrm{K}_{2} \mathrm{CO}_{3}, \mathrm{Cs}_{2} \mathrm{CO}_{3}$ were studied in presence of various grinding auxiliary such as neutral, acidic and basic alumina, and silica gel. But the best result in terms of yield and time was obtained by carrying out the representative reaction in neutral alumina in presence of $\mathrm{K}_{2} \mathrm{CO}_{3}$ under ball-milling at $600 \mathrm{rpm}$ (Table 1, entry 7). It was also observed that when the reaction was carried out in basic alumina without using any base, the yield of the corresponding product was substantially reduced (Table 1, entry 14). Significantly, when the reaction was carried out under identical reaction conditions in a conventional way without ball milling for 30 minutes, the 4-bromodiphenyl disulfide was formed as sole product due to homocoupling of 4-bromothiophenol. This demonstrates the vital role of ball milling for this reaction.

Thus, in a typical reaction procedure, aryl diazonium fluoroborate $(1 \mathrm{mmol})$ and thiophenol $(1.1 \mathrm{mmol})$ were adsorbed onto the surface of neutral alumina and then the mixture was milled in a planetary ball-mill at $600 \mathrm{rpm}$ for a required period of time. Several diversely substituted aryl diazonium fluoroborates underwent reactions with various aryl, heteroaryl and alkyl thiols by this procedure to produce a library of unsymmetrical aryl-aryl, aryl-heteroaryl and aryl-alkyl sulfides. The results are reported in Table 2. Both electron donating (4-OMe) (Table 2, entries 1 and 8 ) and electron withdrawing (4-CN, 4-CHO, 4- $\left.\mathrm{CF}_{3}, 4-\mathrm{NO}_{2}, 3-\mathrm{COCH}_{3}\right)(\mathrm{Table} 2$, entries 2, 47) group substituted aryl diazonium fluoroborates reacted smoothly with a variety of thiols and the functional groups remained inert under the reaction conditions. Moreover, diversely 
substituted thiophenols also underwent reactions without any difficulty. Significantly, sterically hindered thiophenol, 2,6-dimethylthiophenol reacted cleanly with 4-cyanobenzene and 2bromobenzene diazonium tetrafluoroborate to produce the corresponding products (Table 2, entries 2-3). 2-Mercaptopyridine also participated in this reaction to produce the corresponding aryl heteroaryl sulfide (Table 2, entry 4). Aliphatic thiols, benzyl mercaptan and octadecanethiol were successfully converted to the corresponding aryl-alkyl sulfides (Table 2, entries 6 and 8).

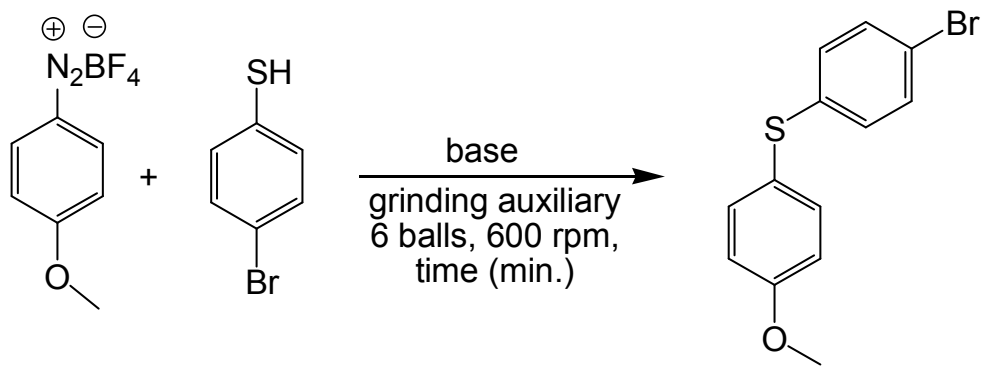

Scheme 1a. Representative reaction for optimization.

Table 1. Optimization of reaction conditions

\begin{tabular}{ccccc}
\hline Entry & Grinding auxiliary & $\mathrm{Base}($ equiv.) & Time (min.) & Yield $^{\mathrm{a}}(\%)$ \\
\hline 1 & Neutral $\mathrm{Al}_{2} \mathrm{O}_{3}$ & $\mathrm{NaOH}(3)$ & 5 & 49 \\
2 & Neutral $\mathrm{Al}_{2} \mathrm{O}_{3}$ & $\mathrm{NaOH}(1)$ & 5 & 58 \\
3 & Neutral $\mathrm{Al}_{2} \mathrm{O}_{3}$ & $\mathrm{NaOH}(0.5)$ & 5 & 61 \\
4 & Neutral $\mathrm{Al}_{2} \mathrm{O}_{3}$ & $\mathrm{KOH}(0.5)$ & 5 & 63 \\
5 & Neutral $\mathrm{Al}_{2} \mathrm{O}_{3}$ & $\mathrm{~K}_{2} \mathrm{CO}_{3}(3)$ & 5 & 97 \\
6 & Neutral $\mathrm{Al}_{2} \mathrm{O}_{3}$ & $\mathrm{~K}_{2} \mathrm{CO}_{3}(1)$ & 5 & 96 \\
7 & Neutral $\mathrm{Al}_{2} \mathrm{O}_{3}$ & $\mathrm{~K}_{2} \mathrm{CO}_{3}(\mathbf{0 . 5})$ & $\mathbf{5}$ & 97 \\
8 & Neutral $\mathrm{Al}_{2} \mathrm{O}_{3}$ & $\mathrm{Cs}_{2} \mathrm{CO}_{3}(0.5)$ & 5 & 95 \\
9 & Neutral $\mathrm{Al}_{2} \mathrm{O}_{3}$ & $\mathrm{~K}_{2} \mathrm{CO}_{3}(0.25)$ & 5 & 81 \\
10 & Neutral $\mathrm{Al}_{2} \mathrm{O}_{3}$ & $\mathrm{~K}_{2} \mathrm{CO}_{3}(0)$ & 5 & 42 \\
11 & Neutral $\mathrm{Al}_{2} \mathrm{O}_{3}$ & $\mathrm{~K}_{2} \mathrm{CO}_{3}(0.5)$ & 3 & 49 \\
12 & Acidic $\mathrm{Al}_{2} \mathrm{O}_{3}$ & $\mathrm{~K}_{2} \mathrm{CO}_{3}(0.5)$ & 5 & 97 \\
13 & Basic $\mathrm{Al}_{2} \mathrm{O}_{3}$ & $\mathrm{~K}_{2} \mathrm{CO}_{3}(0.5)$ & 5 & 37 \\
14 & Basic $\mathrm{Al}_{2} \mathrm{O}_{3}$ & $\mathrm{~K}_{2} \mathrm{CO}_{3}(0)$ & 5 & 44 \\
15 & Silica & $\mathrm{K}_{2} \mathrm{CO}_{3}(0.5)$ & 5 & \\
\hline
\end{tabular}

${ }^{a}$ Yields refer to those of isolated pure (by NMR) products. ${ }^{b}$ Best Condition. 

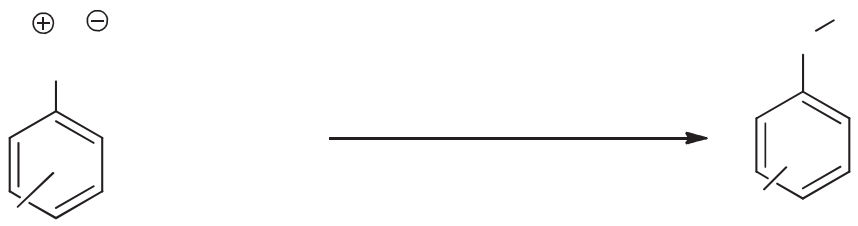

Scheme 2. Synthesis of unsymmetrical sulfides.

Table 2. Synthesis of unsymmetrical diaryl or aryl-alkyl sulfides by ball-milling

\begin{tabular}{cccccc}
\hline Entry & $\mathrm{R}^{1}$ & $\mathrm{R}^{2}$ & Yield $^{\mathrm{a}}(\%)$ & Time (min.) & Ref. $^{\text {b }}$ \\
\hline 1 & $4-\mathrm{OCH}_{3}$ & $4-\mathrm{Br}-\mathrm{C}_{6} \mathrm{H}_{4}$ & 97 & 5 & 28 \\
2 & $4-\mathrm{CN}$ & $2,6-\mathrm{di}-\mathrm{Me}-\mathrm{C}_{6} \mathrm{H}_{3}$ & 83 & 8 & - \\
3 & $2-\mathrm{Br}$ & $2,6-\mathrm{di}-\mathrm{Me}-\mathrm{C}_{6} \mathrm{H}_{3}$ & 80 & 8 & 28 \\
4 & $4-\mathrm{CHO}$ & $2-\mathrm{C}_{5} \mathrm{H}_{4} \mathrm{~N}$ & 93 & 5 & 30 \\
5 & $4-\mathrm{CF}_{3}$ & $4-\mathrm{NO}_{2}-\mathrm{C}_{6} \mathrm{H}_{4}$ & 95 & 5 & 28 \\
6 & $4-\mathrm{NO}_{2}$ & $\mathrm{C}_{6} \mathrm{H}_{5}-\mathrm{CH}_{2}$ & 92 & 5 & 28 \\
7 & $3-\mathrm{COCH}_{3}$ & $4-\mathrm{Br}_{-}-\mathrm{C}_{6} \mathrm{H}_{4}$ & 94 & 5 & - \\
8 & $4-\mathrm{OCH}_{3}$ & $\mathrm{CH}_{3}-\left(\mathrm{CH}_{2}\right)_{17^{-}}$ & 92 & 5 & 28 \\
\hline
\end{tabular}

${ }^{\mathrm{a}}$ Yields refer to those of isolated pure (by ${ }^{1} \mathrm{H}$ and ${ }^{13} \mathrm{C}$ NMR) products. ${ }^{\mathrm{b}}$ This denotes the earlier reference of corresponding products.

To make this procedure more convenient we attempted an in situ diazotization of anilines using $t$-BuONO and subsequent reaction with 4-bromothiophenol. However, the reaction was successful only in case of $p$-anisidine (Scheme 2a).

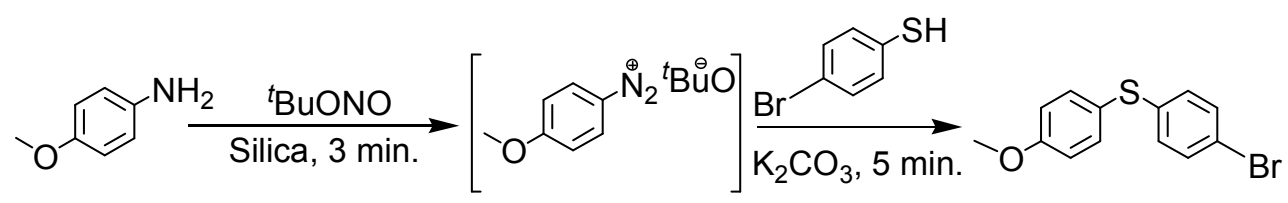

Scheme 2a. One pot procedure for the synthesis of unsymmetrical sulfides starting from $p$ anisidine under ball-milling.

A wide variety of diversely substituted aryldiazonium fluoroborates underwent reactions with phenylselenol under similar reaction conditions to produce the corresponding unsymmetrical aryl phenyl selenides. The results are summarized in Table 3. Both electron donating (4-OMe, 4-Me) (Table 3, entries 1 and 2) and electron withdrawing (3- $\mathrm{Cl}, 4-\mathrm{CO}_{2} \mathrm{CH}_{3}, 4-\mathrm{Br}, 4-\mathrm{CF}_{3}, 4-\mathrm{CN}$ ) (Table 3 , entries 3-7) group substituted aryl diazonium fluoroborates reacted efficiently. The base sensitive functionalities like $\mathrm{COOCH}_{3}, \mathrm{CN}$, remain unaffected under the reaction conditions. 
In general, the reactions are clean and high yielding. Most significantly the reactions are complete within a very short period (5-8 min.). After the reaction was over, the product was purified by simple work-up and column chromatography. The grinding auxiliary, alumina, was washed with ethanol and dried in the oven at $140{ }^{\circ} \mathrm{C}$ for two hours to make it ready for the next run.

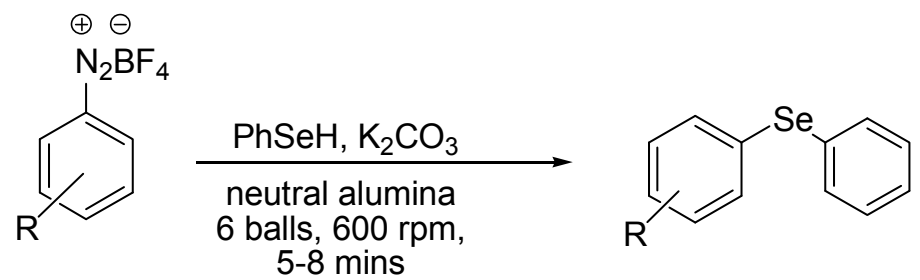

Scheme 3. Synthesis of unsymmetrical selenides.

Table 3. Synthesis of unsymmetrical diaryl selenides by ball-milling

\begin{tabular}{ccccc}
\hline Entry & $\mathrm{R}$ & Yield $^{\mathrm{a}}(\%)$ & Time (min.) & Ref. $^{\mathrm{b}}$ \\
\hline 1 & $4-\mathrm{OCH}_{3}$ & 92 & 5 & 31 \\
2 & $4-\mathrm{Me}$ & 94 & 5 & 32 \\
3 & $3-\mathrm{Cl}, 4-\mathrm{Me}$ & 87 & 5 & 28 \\
4 & $4-\mathrm{CO}_{2} \mathrm{CH}_{3}$ & 81 & 5 & 28 \\
5 & $4-\mathrm{Br}$ & 89 & 5 & 28 \\
6 & $4-\mathrm{CF}_{3}$ & 87 & 8 & 28 \\
7 & $4-\mathrm{CN}$ & 83 & 8 & 28 \\
\hline
\end{tabular}

${ }^{\mathrm{a}}$ Yields refer to those of isolated pure (by ${ }^{1} \mathrm{H}$ and ${ }^{13} \mathrm{C}$ NMR) products. ${ }^{\mathrm{b}}$ This denotes the earlier reference of the corresponding product.

\section{Conclusion}

In conclusion we have developed an improved and efficient methodology for the synthesis of unsymmetrical diaryl, aryl-heteroaryl and aryl-alkyl sulfides and diaryl selenides starting from aryl diazonium fluoroborate and thiol or selenol under ball-milling. The notable advantages of this procedure are high yield and high purity of products, short reaction time (5-8 min.), recyclability of grinding auxiliary, no use of transition metal, catalyst and solvent. We believe that this will make a useful addition to the existing methods for the synthesis of sulfides and selenides. 


\section{Experimental Section}

General. A PM 100 Retsch GmbH, Germany, ball-milling apparatus was used for all reactions.

General Procedure for the Synthesis of Diaryl/ArylHeteroaryl Sulfides. Representative Experimental Procedure for the Synthesis of (4-bromophenyl)(4-methoxyphenyl)sulfane (Table 2, Entry 1). A mixture of 4-methoxy diazonium tetrafluoroborate (272 $\mathrm{mg}, 1 \mathrm{mmol})$, 4bromobenzenethiol (206 mg, $1.1 \mathrm{mmol})$, and $\mathrm{K}_{2} \mathrm{CO}_{3}(69 \mathrm{mg}, 0.5 \mathrm{mmol} / 0.5$ equivalent) adsorbed on neutral alumina ( $3 \mathrm{~g}$ ) was ball-milled in a $25 \mathrm{~mL}$ stainless steel beaker with six balls $(\mathrm{d}=10 \mathrm{~mm}$ ) of the same material at $600 \mathrm{rpm}$ for $5 \mathrm{~min}$ (Caution: The diazonium salts are, in general, susceptible to explosion on heating/grinding, although we did not encounter any such incidence during our investigation. However the reactions should be performed in a closed fume cupboard.). The ball-milling operation was performed using inverted rotation directions, with an interval of 2 minutes and taking an interval break of $30 \mathrm{~s}$. Extraction of the reaction residue by simple elution with ethanol or ethyl acetate followed by evaporation of the solvent gave the crude product, which was purified by a short column chromatography over silica gel (60-120 mesh) using a 9:1 hexane/diethyl ether mixed solvent as eluant to give (4-bromophenyl)(4methoxyphenyl)sulfane as a white solid $(284 \mathrm{mg}, 97 \%)$; mp $66-68{ }^{\circ} \mathrm{C} ;{ }^{1} \mathrm{H}$ NMR $(400 \mathrm{MHz}$, $\left.\mathrm{CDCl}_{3}\right) \delta 3.83(\mathrm{~s}, 3 \mathrm{H}), 6.90(\mathrm{~d}, J=7.2 \mathrm{~Hz}, 2 \mathrm{H}), 7.00(\mathrm{~d}, J=7.2 \mathrm{~Hz}, 2 \mathrm{H}), 7.33(\mathrm{~d}, J=7.2 \mathrm{~Hz}$, 2H), $7.40(\mathrm{~d}, J=6.8 \mathrm{~Hz}, 2 \mathrm{H}) ;{ }^{13} \mathrm{C} \mathrm{NMR}\left(100 \mathrm{MHz}, \mathrm{CDCl}_{3}\right) \delta 55.5,115.3(2 \mathrm{C}), 116.3,119.5$, $129.6(2 \mathrm{C}), 132.0(2 \mathrm{C}), 135.7$ (2C), 138.3, 160.3. These data are in good agreement with those of an authentic sample reported earlier. This procedure was followed for all of the reactions listed in Tables 2 and 3. Almost all of these products are known compounds (see the references in Tables 2,3 ) and were easily identified by comparison of their spectroscopic data with those previously reported. The unknown compounds (Table 2, entries 2 and 7) were characterized by their IR and ${ }^{1} \mathrm{H}$ and ${ }^{13} \mathrm{C}$ NMR spectroscopic data and elemental analysis. These data are given below in the order of their entries in Table 2.

4-(2,6-Dimethylphenylthio)benzonitrile (Table 2, Entry 2). Colorless oil (198 mg, 83\%); IR (neat) 3060, 2970, 2248, 1579, 1476, 1460, 1439, $\mathrm{cm}^{-1}$; ${ }^{1} \mathrm{H}$ NMR $\left(500 \mathrm{MHz}, \mathrm{CDCl}_{3}\right) \delta 2.39$ (s, $6 \mathrm{H}), 6.94(\mathrm{~d}, J=8 \mathrm{~Hz}, 2 \mathrm{H}), 7.22(\mathrm{~d}, J=7.5 \mathrm{~Hz}, 2 \mathrm{H}), 7.287$ (d, $J=7 \mathrm{~Hz}, 1 \mathrm{H}), 7.42(\mathrm{~d}, J=8.5 \mathrm{~Hz}$, $2 \mathrm{H}) ;{ }^{13} \mathrm{C}$ NMR $\left(125 \mathrm{MHz}, \mathrm{CDCl}_{3}\right) \delta 21.7$ (2C), 107.8, 111.6, 119.1, $125.4(2 \mathrm{C}), 128.3,128.9$ (2C), 130.3, 132.5 (2C), 144.0, 145.6. Anal. Calcd. for $\mathrm{C}_{15} \mathrm{H}_{13} \mathrm{NS}$ : C, 75.28; H, 5.47; N, 5.85 . Found: C, 75.24; H, 5.44; N, 5.86.

1-(3-(4-Bromophenylthio)phenyl)ethanone (Table 2, Entry 7). Yellow oil (287 mg, 94\%); IR (neat) 3010, 2850, 1650, 1600, $1280 \mathrm{~cm}^{-1} ;{ }^{1} \mathrm{H} \mathrm{NMR}\left(500 \mathrm{MHz}, \mathrm{CDCl}_{3}\right) \delta 2.57(\mathrm{~s}, 3 \mathrm{H}), 7.30(\mathrm{~s}$, 4H), $7.40(\mathrm{t}, J=8 \mathrm{~Hz}, 1 \mathrm{H}), 7.47(\mathrm{~d}, J=7.5 \mathrm{~Hz}, 1 \mathrm{H}), 7.82(\mathrm{~d}, J=7.5 \mathrm{~Hz}, 1 \mathrm{H}), 7.91(\mathrm{~s}, 1 \mathrm{H}) ;{ }^{13} \mathrm{C}$ NMR $\left(125 \mathrm{MHz}, \mathrm{CDCl}_{3}\right) \delta$ 26.7, 116.3, 127.1, 129.6, 129.7 (2C), 130.4, 133.0 (2C), 133.4, 135.0, 137.0, 138.2, 197.4. Anal. Calcd. for $\mathrm{C}_{14} \mathrm{H}_{11}$ BrOS: C, 54.74; H, 3.61. Found: C, 54.71; H, 3.59 . 
Experimental Procedure for One-pot Diazotization and Coupling for the Synthesis of (4bromophenyl)(4-methoxyphenyl)sulfane from 4-methoxyaniline (Scheme 2a). A mixture of 4-methoxyaniline (123 mg, $1 \mathrm{mmol})$ and ${ }^{\mathrm{t}} \mathrm{BuONO}$ (113 mg, $1.1 \mathrm{mmol}$,) adsorbed on silica gel (3 g) was ball-milled in a $25 \mathrm{~mL}$ stainless steel beaker with six balls $(\mathrm{d}=10 \mathrm{~mm})$ of the same material at $600 \mathrm{rpm}$ for $3 \mathrm{~min}$. The ball-milling operation was performed using inverted rotation directions, with an interval of 2 minutes and taking an interval break of $30 \mathrm{~s}$. Then on the same pot 4-bromobenzenethiol (189 mg, $1 \mathrm{mmol})$ and $\mathrm{K}_{2} \mathrm{CO}_{3}(69 \mathrm{mg}, 0.5 \mathrm{mmol})$ were added simultaneously and the reaction mixture was ball-milled for $5 \mathrm{~min}$. at $600 \mathrm{rpm}$. Extraction of the reaction residue by simple elution with ethanol or ethyl acetate followed by evaporation of the solvent gave the crude product, which was purified by a short column chromatography over silica gel (60-120 mesh) using a 9:1 hexane/diethyl ether mixed solvent as eluant to give (4bromophenyl)(4-methoxyphenyl)sulfane as a white solid (263 mg, 90\%).

\section{Acknowledgements}

We thank CSIR, DST and INSA, New Delhi for financial support.

\section{References}

1. Mugesh, W. W.; Dumont, W. W.; Sies, H. Chem. Rev. 2001, 101, 2125. http://dx.doi.org/10.1021/cr000426w

2. Stuhr-Hansen, N.; Beckers, E. H. A.; Engman, L.; Jansen, R. A. Heteroat. Chem. 2005, 16, 656.

http://dx.doi.org/10.1002/hc.20167

3. Ananikov, V. P.; Zalesskiy, S. S.; Beletskaya, I. P. Curr. Org. Synth. 2011, 8, 2. http://dx.doi.org/10.2174/157017911794407692

4. Beletskaya, I. P.; Ananikov, V. P. Chem. Rev. 2011, 111, 1596. http://dx.doi.org/10.1021/cr100347k

5. Paulmier, C. In Selenium Reagents and Intermediates in Organic Synthesis; Baldwin, J. E., Ed.; Organic Chemistry Series 4; Pergamon Press Ltd.: Oxford, U.K., 1986.

6. Wirth, T. Tetrahedron 1999, 55, 1. http://dx.doi.org/10.1016/S0040-4020(98)00946-6

7. Nishiyama, Y.; Tokunaga, K.; Sonada, N. Org. Lett. 1999, 1, 1725. http://dx.doi.org/10.1021/o1990233z

8. Itoh, T.; Mase, T. Org. Lett. 2004, 6, 4587. http://dx.doi.org/10.1021/o1047996t

9. Suzuki, H.; Abe, H.; Osuka, A. Chem. Lett. 1981, 151. http://dx.doi.org/10.1246/cl.1981.151 
10. Bowman, W. R.; Heaney, H.; Smith, P. H. G. Tetrahedron Lett. 1984, 25, 5821. http://dx.doi.org/10.1016/S0040-4039(01)81695-6

11. Kwong, F. Y.; Buchwald, S. L. Org. Lett. 2002, 4, 3517. http://dx.doi.org/10.1021/o10266673

12. Gujadhur, R. K.; Venkataraman, D. Tetrahedron Lett. 2003, 44, 81. http://dx.doi.org/10.1016/S0040-4039(02)02480-2

13. Cristau, H. J.; Chaband, B.; Chene, A.; Christol, H. Synthesis 1981, 892. http://dx.doi.org/10.1055/s-1981-29636

14. Takagi, K. Chem. Lett. 1985, 1307. http://dx.doi.org/10.1246/cl.1985.1307

15. Takagi, K. Chem. Lett. 1987, 2221. http://dx.doi.org/10.1246/cl.1987.2221

16. Wang, M.; Ren, K.; Wang, L.; Adv. Synth. Catal. 2009, 351, 1586. http://dx.doi.org/10.1002/adsc.200900095

17. Correa, A.; Carril, M.; Bolm, C. Angew. Chem. Int. Ed. 2008, 120, 2922. http://dx.doi.org/10.1002/ange.200705668

18. Ku, X.; Huang, H.; Jiang, H.; Liu, H. J. Comb. Chem. 2009, 11, 338. http://dx.doi.org/10.1021/cc800182q

19. Evers, M. J.; Christiaenes, L. E.; Renson, M. J. J. Org. Chem. 1986, 51, 5196. http://dx.doi.org/10.1021/jo00376a027

20. Engman, L. J. Org.Chem. 1983, 48, 2920. http://dx.doi.org/10.1021/jo00165a026

21. Beletskaya, I. P.; Sigeev, A. S.; Peregudov, A. S.; Petrovskii, P. V. J. Organomet. Chem. 2000, 605, 96. http://dx.doi.org/10.1016/S0022-328X(00)00265-5

22. Prasad, C. D.; Balkrishna, S. J.; Kumar, A.; Bhakuni, B. S.; Shrimali, K.; Biswas, S.; Kumar, S. J. Org. Chem. 2013, 78, 1434. http://dx.doi.org/10.1021/j0302480j

23. James, S. L.; Adams,C. J.; Bolm, C.; Braga, D.; Collier, P.; Friscic, T.; Grepioni, F.; Harris, K. D. M.; Hyett, G.; Jones, W.; Krebs, A.; Mack, J.; Maini, L.; Orpen, A. J.; Parkin, I. P.; Shearouse, W. C.; Steed, J. W.; Waddell, D. C. Chem. Soc. Rev. 2012, 41, 413. http://dx.doi.org/10.1039/C1CS15171A

24. Stolle, A.; Szuppa, T.; Leonhardt, S. E. S.; Ondruschka, B. Chem. Soc. Rev. 2011, 40, 2317. 25. Rodriguez, B.; Bruckmann, A.; Rantanen, T.; Bolm, C. Adv. Synth. Catal. 2007, 349, 2213.

25. Chatterjee, T.; Saha, D.; Ranu, B. C. Tetrahedron Lett. 2012, 53, 4142. http://dx.doi.org/10.1016/j.tetlet.2012.05.127

26. Mukherjee, N.; Ahammed, S.; Bhadra, S.; Ranu, B. C. Green Chem. 2013, 15, 389. http://dx.doi.org/10.1039/C2GC36521A 
27. Chatterjee, T.; Ranu, B. C. RSC Adv. 2013, 3, 10680.

http://dx.doi.org/10.1039/c3ra41996g

28. Mukherjee, N.; Chatterjee, T.; Ranu, B. C. J. Org. Chem. 2013, 78, 11110. http://dx.doi.org/10.1021/j0402071b

29. Kundu, D.; Ahammed, S.; Ranu, B. C. Green Chem. 2012, 14, 2024. http://dx.doi.org/10.1039/c2gc35328h

30. Ohho, S.; Mizukoshi, K.; Komatsu, O.; Nagasaka, M.; Nakamura, Y. Belg., 1983, BE 895994, A1 19830616.

31. Kundu, D.; Ahammed, S.; Ranu, B. C. Org. Lett. 2014, 16, 1814. http://dx.doi.org/10.1021/o1500567t

32. Bhadra, S.; Saha, A.; Ranu, B. C. J. Org. Chem. 2010, 75, 4864. http://dx.doi.org/10.1021/jo100755g 